\title{
LA IRRETROACTIVIDAD DE LOS FALLOS DEL TRIBUNAL DE GARANTIAS CONSTITUCIONALES
}

Alberto Bustamente B.

El presente trabajo tiene por objeto describir el sistema de retroactividad de las sentencias que cont'ene la recientemente promulgada Ley Orgánica del Tribunal de Garantías Constitucionales, y su adecuación al texto de la Carta Politica. Se intenta también una presentación rápida de los elementos de la dinámica ideológico-juridica que podria ubicarse en la base del referido sistema de retroactividad, tanto en lo referido a su tratamiento en el nivel del texto constitucional como el que atañe al tenor de los dispositivos de la Ley.

\section{LA RETROACTIVIDAD EN LA CONSTITUCION DE 1979}

Hay dos normas constitucionales que se refieren a la retro. astividad:

a) El articulo 187 (que trata sobre la retroactividad de las leyes -en la que constituye la segunda definición conceptual que contiene el Capitulo II del Título IV, denominado "De la función legislativa"), y cuyo tenor pertinente es el que sigue: 
"Ninguna ley tiene fuerza ni efectos retroact:vos, salvo en materia penal, laboral o tributaria, cuando es más favo:able al reo, trabajador o contribuyente, respectivamente".

b) El artículo 300, inserto en el Título $\mathrm{V}$ (denominado "De las garantias constitucionales"), y cuyo texto es el que a continuación se transcribe:

"No tiene efecto retroactivo la sentencia del Tribunal que declara inconstitucional una norma en todo o en parte".

El primer comentario que merece el tratamiento, a nivel del texio constitucional, del concepto de retroactividad es que, en iérrainos matcriales, resulta por lo menos cuestionable que la Constituc'ón contenga dispositivos que otros sistemas constitucionales no han tratado, han remitido a un nivel legal o simplemente han excluido de su texto (1).

Si, por ejemplo, constatamos que el Código Civil Español contiene normas de carácter transitorio que tratan diferencialmer!te varias situaciones de lo que latamente se entende por retroactividad según se refieran a materias testamentarias, reales, en las que se encuentren presentes consideraciones relativas al momento en que se produjeron los hechos o se generó el derecho, podremos concluir al menos que el concepto de retroactividad no es tan uniEn tanto no existia un sistema de control de la constitucional:que pretende definir la eficacia temporal de las leycs o de las sentencias de la jurisdicción constitucional.

Es posible que consideraciones ideológ cas cxpliquen la presencia de un concepio juridicamente cquivoco en un texto constitucional. No es del todo castal, en ese sentido, que el texto cons-

(1) Buena parte de las normas contenidas en el titulo preliminar del Código Civil vigente han sido objeto de tratamento en el texto de la Constitución de 1979. Esta orientación hacia la "constitucionalización", sin embargo, también se ha expresado en el caso del concepto de retroactividad, que el Código Civil no trata y que la Constitución recoge hasta en dos ccasiones. Ello marca una importante diferencia con otrcs sistemas juridicos, en los que la retroactividad ha constituido una preocupación conformada en torno a la aplicación temporal de la ley civil y no un concepto normado en el nivel constitucional. 
titucional vigente siga, en parte, al inmediatamente anterior (2). En tanto existia un sistema de control de la constitucionalidad de las leyes, y el Poder Judicial tampoco había sido capaz de (ni requerido para) vigilar la preminencia del texto constitucional sobre el legal, podemos por lo pronto presumir que, en los hechos, la noción de irretroactividad ha sido instrumentalmente útil para detener las posibilidades de que el sistema judicial pueda operar desatando su eficacia en situaciones pasadas. La tetroactividad, además de ser equivoca como concepto a ser empleado en un texto constitucional, ha sido lo suficientemente vulgarizada como para que se convierta en un concepto poco menos que equivalente al de "arbitrariedad" o "afectación de derechos".

\section{LA REGLA GENERAL Y LAS EXCEPCIONES}

El sistema constitucional peruano, a diferencia del Código $\mathrm{Ci}$. vil español, contiene un precepto general que dispone que las ieyes no tengan efecto retroactivo, y una norma excepcional, que admite la retroactividad legal si favorece a los reos, a los trabajadores o a los contribuyentes. Las disposiciones transitorias del Código Civil español, al igual que muchas otras legislaciones nacionales, definen la aplicación temporal de la nueva ley civil en función de su particularidad, guiadas, por ejemplo, por el principio de que la nueva ley no puede afectar relaciones juridicas generadas en el pasado en un nivel contractual (3).

El texto de la Constitución merece un segundo comentario: los únicos sujetos de derecho que gozan de la retroactividad de la ley son los reos, los trabajadores o los contribuyentes. Una primera lectura indicaria que la retroactividad tiene una significación básicamente protectiva: las partes más débiles de las relaciones juridicas de contenido penal, laboral o tributario son los reos, los trabajdores y los contribuyentes, respectivamente. Claro,

(2) La Constitución Politica de 1933 contenia, en su articulo 25\%, una norma similar a la que contiene la primera parte del artículo $187^{\circ}$ de la Constitución vigente.

(3) Ea regla transitoria segunda del Código Civil español dispone que "los actos y contratos celebrados bajo el régimen de la legislación anterior, y que sean válidos con arreglo a ella, surtirán todos sus efectos según la misma, con las limitaciones establecidas en estas reglas". 
nadie puede explicar for qué razón los presos, los obreros y emplcados y las empresas mineras - que son también contribuyeniesgozan de granjerias constitucionales de que no disponen los inqui. linos, los campesinos sin ticrra, los profesionales gremialmente enterdidos o los a!imentistas. En otras palabras, el aparente afán pictactivo del texto constitucional se ve casi totalmente desmentido por el hecho de que el ámbito de protección ha $s$ do definido en función de una conceptualización abstracta que resulta muy cuesticnable, y no con arreglo a una real constatación acerca de quiénes scn los sujetos merecedores en efecto de protección constitucional cuando se trata de la aplicación de las lzyes "hacia atrás", y descle luego, en qué situaciones es posible hacerlo y en qué otras as lógico, imposible o arbitrario.

\section{EL CONCEPTO DE "RETROACTIVIDAD" EN CUESTION}

El concepto de retroactividad ha sido duramente cuestionado por importantes exponentes de la doctrina del derecho público, no tanto por no sntenderse la posibilidad de otorgársele un significado juridico preciso, cuanto por su ineficacia cuando se le convierte en preccpto normativo genérico e irreductible.

"Ecta cuestión (la de la esfera de imperio temporal de las leyis -nota del autor) no puede, como frecuentemente se supoixe, resolverse por el principio de que las leyes no tienen efecto réroactivo', pues si la ley sólo tiene efecto a parrir de su entrada en vigor y sólo para lo futuro, es perfectamerte compatble con esto que la ley derogue o modifique tamb'én desda ahora y para lo fututo las relaciones que aun hoy shibsisten (que nacieron antes). El que una ley que hoy entra en vigor me quite o empeore desde hoy una propiedad s.e yo tina, puede ser injusto, pero indudablemente no es in efecio retroactivo" (4).

Clonde de Pasquier, insospechable de manejar segundas ir scncicacs iccologicas, relativiza aún con más énfasis el precepto romatio gereralizante acerca de la retroactividad de las leyes:

"El principio de la no retroactividad es una regla de mora1

(4) EINNECCERUS-Kipp Wolff.

"Tratado de Dercho Civil", Tomo I, p. 227. 
legislativa; pero no deriva de la naturaleza de las cosas. La retroactiv:dad es posible y no podría decirse qur: el legisla dor no la emplee nunca. El alcance del principio es, por otra parte, variable según las diferentes ramas del derech." (5).

En el contexto de un tono evidentemente más analítico. se han distinguido niveles o grados de retroactividad:

“...La retroactividad puede entenderse en varios sentidns; - como aplicación de la ley nueva a hechos, no solamente realizados, sino también agotados bajo el imperio de la ley anantigua, en cuanto hayan producido todos sus defectos; - como aplicación de la ley nueva a todas las controversias que surjan o estén todavía pendientes, en el momento en que la misma entra en vigor, aun cuandio conciernan a hechos realizados bajo el imperio de la ley antigua;

--Finalmente, como aplicabilidad a hechos nuevos, que se verifican, por primera vez, bajo el imperio de la ley nueva, pero que se encuentren en relación con hechos anteriores y parece que el más apropiado sea el segundo significado" (б).

En el contexto de un problema conceptual como el que la mayor parte de quienes han tratado el tema han descrito (problcma conceptual que se contrae a que la irretroactividad constituye un mandato genérico irreductible), el articulo 187 de la Constitución Política del Perú agrava aún más el probiema, al mencionar excepciones formuladas en función de la nicesidad protectiva que merecen cierto tipo de relaciones juridicas como la penal. la tributaria y laboral en cuanto atañen al reo, contribuyent $=$ o tra. bajador, respectivamente.

\section{LOS LIMITES DE LA RETROACTIVIDAD}

El resguardo de la seguridad jurídica como imperativo del Derecho como tal (7), ha servido de base para que. en cfecto. 1a

(5) Du Pasquier, Claude...

"Introducción a la Teoria General del Dercho y a la Filcscfia".

(6) MESSINEO, Francisco...

"Derecho Civil y Comercial", Tomo I. p. \$9.

(7) RADBRUCH, Gustavo...

"Introducción a la Filosofia del Derecho".

Fondo de Cuitura Eccnómica, México, 1965. 
irretroactividad sea la regla y la retroactividad la posibilidad excepcional. Por ejemplo, parece ex:stir consenso en la doctrina en el sentido de que la retroactividad puede ser inevitable o incluso conveniente en determinadas hipótesis de excepción. Pero existe igualmente un importante consenso en torno a la inconveniencia o la injusticia que conlleva la aplicación retroactiva de la ley cuando se desarrolla en sus potencialidades máximas y sin respecto dc los "derechos adquiridos" (8). Las áreas que son particularmente sensibles al escozor que produce la retroactividad en los tratadistas son el área contractual y el área judicial.

El Código Civil español, en una de sus disposiciones transitorias, establece con contundencia, por ejemplo, que "los actos y contratos celebiados bajo el régimen de la legislación anterior, y que sean válidos con arreglo a ella, surtirán todos sus efectos segín la misma, con las limitaciones establecidas en estas reglas" (9). En otras palabras, salvo excepciones, una regla importante es que no cabe la retroactividad en la esfera contractual, escenario de la actitud libre y espontánea de quienes expresan voluntades que conducen al nacimiento de obligaciones. Lo ya sentenciado y lo ya juzgado suele ser también una segunda esfera que no admite la aplicación retroactiva de la nueva ley, salvo en el te. rreno de la benignidad de la ley penal.

"Pero, por regla general, no sabe suponer que la ley, para la cual se ha p:escrito el efecto retroactivo (...), se refiera a las relaciones definitivamente fijadas o desenvueltas en virtud de sentencia firme, transacción, renuncia, reconocimiento, cumplimiento, compensación, etc., y que por tanto deba destruirse a posteriori su estado definitivo" (10).

(8) La intocabilidad $\mathrm{d}_{\mathrm{e}}$ los "derechos adquiridos" ha sido severamente cuestionada por Enneccerus-Kipp-Wolf. Dicen: "Este principio, si bien da una solución relativamente clara a nuestro problema, es falso en muchos casos. Cambiaria totalmente de sentido, por ejemplo, el que una ley que declara redimibles ciertos censos o que deroga el derecho del propietario a recoger los frutos que cayeran del árbol de su finca sobre la finca vecina, no se aplicase a los censos existentes o a la propiedad ya existente" (op. cit., p. 227).

(9) Regla transitoria segunda del Código C:vil Español.

(10) ENNECCERUS-KIPP.WOLF...

op. cit., p. 228. 


\section{LA PREOCUPACION POR LA RETROACTIVIDAD}

Que la irretroactividad del derecho fue un tema digno de preocupación intensa de los constituyentes, no sólo lo prueba el texto del artículo 187, al referirse a las leyes, sino también el texto del artículo 300 , al ser aplicable precisamente a los fallos del Tribunal de Garantias Constitucionales. "No tiene efecto retroactivo la sentencia del Tribunal que declara inconstitucional una norma en todo o en parte" dice el texto, marcando así una notoria diferencia con el tratamiento que ha merecido la retroactividad al referirse a las leyes en la propia Constitución (articiulo 187). En este último caso la prohibición de la retroactividad senala expresamente la existencia de tres excepciones.

Es probable que en la circunstancia anotada (es decir, que la Constitución no haya previsto excepciones al principio general de la irretroactividad cuando se trata de los fallos del Tribunal de Garantias Constitucionales, mientras que si lo hace referirse a las leyes), hayan encontrado amparo los legisladores al no repetir -en el texto de la Ley Orgánica del Tribunal- una norma genérica que estableciera, como el artículo 187 de la Constitución, que sus fallos sí pueden tener efecto retroactivo si se refieren a materias penales, laborales o tributarias cuand') favorezcan al reo, al trabajador y al contribuyente, respectivamente. En principio, el precepto genérico de la irretroactividad de los fallos debiera haber sido objeto de excepciones adecuadamente formuladas, ya que la negación total de la retroactividad de los fallos expedidos en torno a materias constitucionales implica la ieptación de que las normas inconstitucionales pueden regir sin problemas. A su vez, la aceptación de que las normas viciadas de inconstitucionalidad puede regir sin problemas, conduce a la consagración formal de una brecha en el respeto a la jerarquia de las fuentes del Derecho, que equivale a establecer que las normas de inferior jerarquía que contravienen la Constitución son válidas hasta el momento en que sean declaradas inconstitucionales. Tal declaración surte efecto sólo hacia adelante -en tanto entre en vigor una norma derogatoria - lo cual no impide que la incons. titucionalidad, finalmente, no sólo no sea objeto de sanción :ino que incluso se le asigne vigencia jurídica. 


\section{LA REVISION DE LOS PROCESOS JUIDICIALES FENECIDOS}

Los legisladores preocupados por la retroactividad cor:eticron un doble error: no interpretar adecuadamente el articulo 300 de la Constitución, estableciendo al menos para los fallos una norma stmilar que la que contempla la Constitución para las leyes: que excepcionalmente tengan efecto retroactivo. Al parecer, creyeron que era posible hacerlo a través del articulo 41 de la Ley, que establece textualmente:

"Las sentencias declaratorias de inconstitucionalidad no permiten revivir procesos fenecidos en los que se haya hecho aplicación de las normas declaradas inconstitucionales, salvo en las materias previstas en el artículo 187, segunda parte, de la Constitución".

Alli también residió el segundo error significativo de los leg sladores: recoger el artículo 187 de la Constitución (es decir, las excepciones al precepto genérico de irretroactividad) no para formular también un precepto genérico que contemplara excepciones, sino para ubicar estas últimas dentro de la hipótesis de un procieso judicial fenecido. En otras palabras, la ley es timida al no repetir el artículo 187 de la Constitución para los fallos del Tribunal - lo cual definitivamente no habria entrañado inconstitucionalidad--, pero es simultáneamente arrogante al admitir la posibilidad de que los juicios sentenciados puedan ser revividos si en ellos se hizo aplicación de normas posteriormente declaradas inconstitucionales. La ley no es capaz de ensayar un precepto genérico expuesto a matices excepcionales cu'dadosamente estudiados, pero tampoco muestra mayores reparos en transgredir, sin recato alguno y en via de excepción, la garantia de la administración de justicia en virtud de la cual no es permitido la reapertura de procesos judiciales fenec dos (inciso li) dal artículo 233 de la Constitución).

Podemos ilustrar con algunos ejemplos esta grave contradicciơn. Un sujeto al que administrativamente se le negó una concesión (en virtud de una norma legal que posteriormente fue declarada inconstitucional), no puede pretender que el fallo del Tri- 
bunal que la declare inconstitucional sirva de fundamento para la iniciación de un juicio declarativo de su derecho en relación al pasado, mientras que un sujeto vencido en juicio por aplicación de una norma que posteriormente fue declarada inconstitucional puede reabrir el juicio y lograr asi la retroactividad de la nueva norma derogatoria o, para decirlo de otro modo, las decisiones firmes de los jueces pueden ser revisadas en virtud de la declaración posterior de inconstitucionalidad de una norma; pero, si no existió juicio, las autoridades administrativas no están obligadas a modificar su criterio, por la declaración posterior de inconstitucionalidad que pueda sufrir una Ley mediante sentencia del Tribunal.

\section{LA "COSA JUZGADA" EN LA LEY}

El principio de la cosa juzgada sufre grave afectación por el texto del artículo 41 de la Ley del Tribunal. Sólo a guisa de ejemplo, se podria pensar en que sesenta diputados soliciten al Tribunal que declare precisamente la inconstitucionalidad el articulo 41 a que nos estamos refiriendo, por afectar seriamente normas constitucionales que garantizan la vigencia y observancia de la cosa juzgada. El Tribunal declara fundada la demanda y deroga a través de su sentencia el artículo 41 de la Ley. Los juicios que se hubieren revivido durante la vigencia de la norma derogada no podrian dejar de tramitarse, porque se estaria transgrediendo el artículo 300 de la Constitución. Los jueces entonces, tendrian que resignarse a aplicar, llegado el momento, la ley derogada, e inconstitucional que permite la revisión de los procesos judiciales fenecidos, y dentro de la vigencia de la derogatoria. Para decirlo de otro modo, la afectación de los derechos adquiridos es de tal naturaleza que gracias a esta equivocada fórmula los fallos del Tribunal no sólo pueden ocasionar la revisión de los procesos judiciales fenecidos, sino también obligar a los jueces a que apliquen, incluso después de tales fallos, la ley derogada por estos últimos debido a su inconstitucionalidad. $O$, para señalarlo de otra manera, un entrampamiento constitucional-legal seguramente no deseado, pero no por ello menos acabado y perfecto, en virtud del cual todo el tinglado normativo que impide la retrcactividad posibilita y determina la ultra-activ dad de la norma inconstitucional. 


\section{LA LEY Y LOS LIMITES \\ DE LA FUNCION JURISDICCIONAL}

Si examinamos el resto de los preceptos de la nueva Ley Grgánica del Tribunal de Garantías Constitucionales que, de alguna manera $u$ otra, encierran en su significado normativo esta preocupación desmedida por los efectos retroactivos de los fallos, el cuadro de una explicación básicamente ideológica nos será, por cierto, más digerible. Los transcribimos a continuación:

1. "Los jueces suspenden la tramitación de los procesos de acción popular fundados en normas cuya inconstitucionalidad se halle en trámite ante el Tribunal, hasta que éste expida su resolución" (11).

2. "El plazo previsto por esta Ley para interponer la acción de inconstitucionalidad comienza a contarse desde el día en que quede constituido el Tribunal, cuando las leyes, decretos legislativos o disposiciones que origenen la acción fueran anteriores a aquella fecha y no hubieran agotado sus efectos" (12).

No debe pensarse que la norma transcrita en el punto 1) constituye un dispositivo aislado. La primera parte del mismo artículo 39: de la Ley dispone que "los jueces no pueden dejar de aplicar una norma cuya inconstitucionalidad haya sido desestimada por el Tribunal". Conviøne preguntarse: ¿a titulo de qué el legislador consideró conveniente interferir en la función judicial? El enunciado del texto transcrito es claro en apariencia, pero ¿qué implica que se someta a los jueces a discernir el resultado de un planteamiento en abstracto?. Por definición, la "acción de inconstitucionalidad implica, trátese de cuestiones formales o de problemas sustantivos, que se confronte la normatividad constitucional con una normatividad de inferior jerarquia (leyes, decretos legislativos, normas regionales de carácter general y ordenanzas municipales).

(11) 2do. párrafo del artículo 39 de la Ley No 23385 (Ley Orgánica del Tribunal de Garantias Constitucionales).

(12) Tercera Disposición Transitoria de la Ley Orgánica del Tribunal de Garantias Constitucionales. 
Confrontación de normatividades, en suma. El litigio judicial, en cambio, suele plantearse en términos de concreción tales que la resolución deba apreciar situaciones de hecho -configuradoras de una nueva situación de derecho- que la simple confrontación nor. mativa no hace aparecer (13).

La noción de inconstitucionalidad frente a una hipotética Ley de Servicios Públicos, por ejemplo, podria ser desestimada por el Tribunal, en vista de que no se atenta contra el derecho de huelga. Pero, si en un acontroversia judicial la aplicación de la norma cuya inconstitucionalidad fuese desestimada por el Tribunal apareciese ofendiendo visiblemente el derecho de sindicalización de los servidores públicos, ¿no se está pretendiendo acaso obligar al juez, por el mandato de la norma transcrita, a aplicar la ley a pasar de su inconstitucionalidad? En los casos de acción popular, el encasillamiento que determina la segunada parte del artículo $39^{\circ}$ obliga a los jueces a suspender los procesos pendientes, aún cuando las materias sujetas a la jurisdicción constitucional, las prerrogativas inherentes a la jurisdicción en nuestro ordenamiento constitucional: la de ser única y exclusiva (14) y la consistente en preferir la Constitución a las normas de inferior jerarquia (15), en caso de conflicto entre ellas.

\section{EL "AGOTAMIENTO DE LOS EFECTOS"}

En el segundo dispositivo transcrito es más perceptible la utilización, en su acepción vulgar, de un concepto teórico -el del agotamiento de los efectos- que los tratadistas han construido y analizado con respecto de la irretroactividad de la ley futura (y no de una sentencia futura, como en este caso) (16). Cabe

(13) Resulta tan claro que la apreciación $\mathrm{d}_{e}$ la inconstitucionalidad en el interior de un litigio supone una operación lógica $-y$ jurisdiccional-radicalmente distinta a la confrontacón de textos normativos, que algunos sistemas juridicos simplemente no contemplan mecanismos de control constitucional que no sean los judiciales ordinarios que aparecen en las controversias concretas.

(14) Cfr. articulo 233 inciso f) de $I_{a}$ Constitución Politica de 1979.

(15) Cfr. articulo 336 de la Constitución Politica de 1979.

(16) Cuando autores como Messineo distinguen grados o riveles de retroactividad, mencionan la situación extrema de que se pretenda la apli- 
imaginar la no tan imposible hipótesis de que un Concejo Municipal exp da una ordenanza inconstitucional con el ánimo deliberado de que sus efectos "queden agotados" ciertamente antes de que se puedan reunir cincuenta mil firmas o que uno de los Poderes del Estado impugne la norma. La aplicación de la ley, en un caso asi de concreto, impediría -ciertamente transgrediendo la Constitución - que los ciudadanos tuvieran medios de defensa constitucionales frente al atropello que "agota sus efectos" inmediatamente después, o muy poco después de producidos.

\section{SENTENCIAS INHIBITORIAS}

Las notorias preocupaciones de los legisladores en torno a la retroactividad se expresan en textos normativos que encierran contradicciones, vacios y conceptos cuya estimación vugarizada - por demás probable en un contexto ideo-juridico como el peruano-- puede conducir a un cúmulo de resoluciones inhibitorias, limitándose de esta manera el papel del Tribunal al punto de convertirsele en lo contrario de lo que debió ser: un órgano efectivamente encargado del control de la constitucionalidad. No es que se le nieguen de otro lado, defectos a un texto constitucional que no tenia razón alguna para referirse a los efectos y fuerza retroactiva de los fallos del Tribunal (como tampoco la tenia al tratar el mismo tema referido a las leyes).

"De suerte, pues, que las fórmulas de la irretroactividad del respeto a los derechos adquiridos deben traducirse y se traducen en otras más concretas y más aptas para su fácil e inmediata aplicación" (17).

cación de la ley nueva a hechos "agotados" bajo el imperio de la ley antigua. Se refieren - -dentro del discurso juridico en que se ubican a presupuestos de hecho que eran necesarios y suficientes para que $e$ ! derecho naciese, $y$ no a relaciones que están en proceso de formación (Messinco, Op. cit, p. 89). El concepto de "agotamiento" tienc, pues, una acepción doctrinaria precisa que el legislador pudo haber adoptado en esa dimensión, pero que finalmente parece recoger sólo en su versión vulgarizada, al tratarla en una disposición transitoria sólo referida a leycs previas al funcionamiento del Tribunal.

(17) ENNECCERUS-KIPP-WOLF

op. ct., p. 236. 
O, como acertadamente anota Messineo:

"Donde existe un adecuado derecho transitorio (...) no quedan espacios libres respecto de los cuales deba preguntarse intérprete si la nueva ley es -o no-retroactiva" (18).

Si la retroactividad resulta siendo de complicado, difícil y problemático tratamiento legal, su incorporación a nivel constitucional es un punto de partida lamentable. En él se han amparado, sin duda, legisladores cuya cautela por el pasado juridico no por inconveniente es menos notoria.

Más allá, sin embargo, de que la Constituc'ón no debió iáberse referido ni a la retroactividad de la ley ni a la de los fallos del Tribunal, es obvio que los legisladores pudieron haber construido creativamente un esquema juridico más amplio y flexible. Frente a disposiciones procesales que definitivamente encarnan una percepción protectiva del ciudadano en relación a situaciones normativas o judiciales de inconstitucionalidad, la propia ley que los contiene tiene paralelamente un punto de partida conceptual más bien restringido y limitante, al punto que la supuesta fidelidad al texto constitucional deviene en la significativa contradicción consistente en desconocer el principio de la cosa juzgada.

La juridicidad del docenio militar estuvo plagada de normas que los juristas de "opos ción" calificaron prontamente como "retroactivas", condenándolas por transgredir la Constitución que ellos denominaban vigente. Esos mismos juristas, instalados ahora armoniosamente en varios sectores del aparato del Estado, han sido sin duda los progenitores -o, al menos. los encubridores-de un texio legal que resulta definitivamente restrictivo con respecto al texto constitucional, aún considerando los defectos que este último tiene.

(18) MESSINEO, Francesco

Op. cit., p. 92. 
Tanto la irretroactividad de la ley como la de los fallos del Tribunal trasuntan una desconfianza básica en lo que, en términos generales, se conoce como la administración de justicia. La judicatura -temerosa de la Espada de Damocles del prevaricatopodrá asirse de la Constitución y de la ley para no afectar sustancialmente relaciones juridicas del pasado. Para regirse siempre - con sentido de la oportunidad impuesta- por la ley vigente. Para no imaginar excepciones. Para no crear jurisprudencia en virtud de las especificidades. ¿Alguien duda de que se ha tenido en cuenta ese comportamiento judicial tan peruano al redactarse normas que impiden que los jueces testituyen el derecho ya vulnerado?. ¿No estaremos acaso ante un "borrón y cuenta nueva" ( $\tan$ peruano) tratándose de materias constitucionales? ¿No se le están concediendo granjerias ilimitadas al Poder? iNo se valdrán de esos dispositivos limitantes quienes capturen el poder contra la Constitución? ¿Se podrá exigir rendición de cuentas a quienes consagren la inconstitucionalidad por mandato de una ley?. Las respuestas que tales preguntas tienen no convocan a una forzada discusión en abstracto, sino a interrogantes concretas... En definitiva, iNo pudo, acaso, legislarse mejor?. 